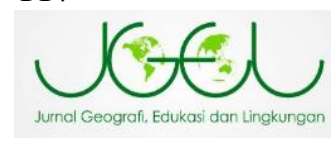

\title{
Model Pembelajaran Penginderaan Jauh Di Sekolah Menengah Atas
}

\author{
Lili Somantri ${ }^{1}$, Dan Riki Ridwana ${ }^{1 *}$ \\ ${ }^{1}$ Program Studi Sains Informasi Geografi, Fakultas Pendidikan Ilmu Pengetahuan \\ Sosial, Universitas Pendidikan Indonesia, Jl. Dr. Setiabudi No. 229 Bandung, Indonesia. \\ *E-mail: rikiridwana@upi.edu
}

Received: 17052021 / Accepted: 3006 2021/ Published online: 27072021

\begin{abstract}
ABSTRAK
Pembelajaran penginderaan jauh di sekolah menengah atas belum mampu dilakukan secara maksimal. Dikarenakan berbagai keterbatasan diantaranya guru kurang memahami materi yang behubungan dengan penerapan atau aplikasi dari konsep penginderaan jauh, guru kurang menguasai penggunaan perangkat lunak penginderaan jauh, guru masih menggunakan metode ceramah dan tugas, dan guru menggunakan media pembelajaran yang kurang lengkap. Untuk memberikan solusi pada permasalahan pembelajaran penginderaan jauh di sekolah, maka artikel ini akan mencoba memaparkan hasil penelitian tentang model pembelajaran penginderaan jauh yang paling tepat agar dapat diterapkan oleh guru dan meningkatkan kualitas pembelajaran. Artikel ini memaparkan model pembelajaran penginderaan jauh di sekolah dengan metode mengulas beberapa hasil penelitian. Analisis pembahasan dilakukan dengan cara mendeskripsikan model pembelajaran penginderaan jauh, pendekatan pembelajaran, dan metode pembelajaran yang sesuai dengan materi kurikulum 2013. Hasil kajian menunjukkan bahwa model pembelajaran untuk materi penginderaan jauh kelas X paling tepat menggunakan model pembelajaran berbasis proyek (project based learning), kelas XI menggunakan model pembelajaran berbasis masalah (problem based learning), dan kelas XII paling tepat menggunakan model pembelajaran berbasis penelitian (research based learning). Hasil temuan model pembelajaran ini dapat diterapkan pada materi penginderaan jauh berdasarkan jenjang Pendidikan.
\end{abstract}

Kata Kunci: Model Pembelajaran Penginderaan Jauh, Metode Pembelajaran, Materi Penginderaan Jauh

\section{ABSTRACT}

Remote sensing learning in Senior High Schools has not been able to be carried out optimally. This is caused by various limitations, including teachers who do not understand material related to the application of remote sensing concepts, teachers do not master the use of remote sensing software, teachers still use lecture and assignment methods, and teachers use incomplete learning media. To provide solutions to remote sensing learning problems in schools, this article will try to describe the results of research on the most appropriate remote sensing learning model so it can be applied by teachers and improve the quality of learning. This article describes a remote sensing learning model in schools with a method of reviewing some of the research results. Discussion analysis is carried out by describing the remote sensing learning model, learning approach, and learning methods that are in accordance with the 2013 
curriculum ma-terial. The results of the study show that the learning model for remote sensing material in class $X$ is most appropriate using a project-based learning model, class XI uses a problem-based learning model, and class XII is most appropriate using a research-based learning model. The findings of this learning model can be applied to remote sensing material based on education level.

Keywords: Learning Models, Learning Methods, Remote Sensing Materials

\section{PENDAHULUAN}

Metode

Pembelajaran

penginderaan jauh perlu dikuasi oleh guru agar dapat menjalankan pembelajaran untuk mendongkrak kualitas pembelajaran (Selesho, 2012). Guru perlu mengembangkan metode, media, dan sumber belajar yang sesuai dengan tujuan dan karakteristik materi penginderaan jauh. Untuk memutuskan model, pendekatan, dan metode pembelajaran yang tepat, maka harus diperhatikan kompetensi dasar, tujuan pembelajaran, materi pembelajaran, kondisi siswa, dan kemampuan guru itu sendiri.

Pembelajaran penginderaan jauh di sekolah hingga saat ini belum mampu dilakukan secara maksimal (Ruhyati \& Banowati, 2019). Hal tersebut dilatarbelakangi oleh berbagai keterbatasan diantaranya guru kurang memahami materi yang behubungan dengan penerapan atau aplikasi dari konsep penginderaan jauh, guru kurang menguasai penggunaan perangkat lunak penginderaan jauh, guru masih menggunakan metode ceramah dan tugas, dan guru menggunakan media pembelajaran yang kurang lengkap. Selain itu, permasalahan lainnya yang penulis temukan di lapangan adalah terbatasnya fasilitias laboratorium untuk praktikum, keterbatasan pembelajaran daring saat pandemic covid-19, waktu yang tersedia untuk pembelajaran masih kurang, siswa kurang memahami materi penginderaan jauh dan masih merasa asing dengan materi penginderaan jauh. Maka dari itu dibutuhkan model pembelajaran penginderaan jauh yang tepat untuk memaksimalkan hasil belajar siswa di sekolah.

Model pembelajaran penginderaan jauh menunjukkan hasil terbaik ketika dilaksanakan secara tatap muka, dibandingkan menggunakan model pembelajaran campuran (blended learning) dan pembelajaran daring (Manzano-Agugliaro dkk., 2016). Penelitian lainnya menunjukkan bahwa model pembelajaran penginderaan jauh berbasis proyek (project base learning) tepat diterapkan karena siswa lebih aktif dan pengaturan eksperimental materi penginderaan jauh didasarkan pada konsep dan ide yang berasal dari siswa (Mountrakis \& Triantakonstantis, 2012). Lebih spesifik lagi model pembelajaran penginderaan jauh yang dikombinasikan dengan UAV (Unmanned Aerial Vehicle) dan flipped learning menurut studi mampu meningkatkan motivasi, komitmen terhadap tugas, interaksi antara guru dan siswa, perolehan konten didaktik, partisipasi siswa aktif, mana-jemen belajar siswa, sikap siswa terhadap konten, dan prestasi akademis mereka (Belmonte dkk., 2019; Cerezo dkk., 2015; Huang dkk., 2019; Kwon \& Woo, 2017; Núñez dkk., 2020; Tse dkk., 2019). Merujuk pada penelitian-penelitian di atas dapat disimpulkan bahwa penguasaan guru terhadap model pembelajaran penginderaan jauh berpengaruh terhadap peningkatan hasil belajar siswa.

Untuk memberikan solusi pada permasalahan pembelajaran penginderaan jauh di sekolah, maka artikel ini akan mencoba memaparkan hasil penelitian tentang model pembelajaran penginderaan 
jauh yang paling tepat agar dapat diterapkan oleh guru dan meningkatkan kualitas pembelajaran.

\section{METODE PENELITIAN}

Artikel ini memaparkan model pembelajaran penginderaan jauh di sekolah dengan cara mengulas beberapa hasil penelitian (Literature Review). Lieterarture Review merupakan uraian kajian kritis dalam pembahasan tema yang telah ditulis oleh para ahli dibidang tertentu (Fathrunnadi Shalihati dkk., 2014). Metode tersebut lazim digunakan diantaranya pernah dilakukan oleh (AbdelRahman \& Ahmed, 2008), (Ridwana \& Himayah, 2020), dan lain-lain. Tujuannya untuk memberikan informasi yang akurat dan mendasar berkaitan dengan model pembelajaran di sekolah, sehingga dapat diterapkan oleh guru. Analisis pembahasan dilakukan dengan cara mendeskripsikan model pembelajaran penginderaan jauh, pendekatan pembelajaran, dan metode pembelajaran yang sesuai dengan materi kurikulum 2013.

\section{HASIL DAN PEMBAHASAN}

Kerangka Teoritis Model Pembelajaran

Model pembelajaran ialah bentuk pembelajaran yang terencana dari awal sampai akhir yang dibawakan secara unik oleh guru (Bergsteiner \& Avery, 2014; Cheung \& Delavega, 2014; Gréhaigne dkk., 2006; Korkmaz \& Karakus, 2009; Sugiharto, 2020). Di dalam model pembelajaran terdapat strategi pencapaian kompetensi siswa dengan pendekatan dan metode pembelajaran. Pendekatan pembelajaran adalah konsep dasar yang mewadahi, menginspirasi, menguatkan, dan melatari metode pembelajaran dengan cakupan teoritis tertentu (Alkin-Sahin, 2015; Urhahne, 2020). Pendekatan pembela-jaran yang mendalam lebih dari sekedar menghabiskan banyak waktu untuk belajar (Everaert dkk., 2017), lebih dari itu harus dipilih yang dianggap paling efektif (Erskine \& Johnson, 2012). Metode pembelajaran adalah prosedur, urutan, langkah-langkah, dan cara yang digunakan guru dalam mencapai tujuan pembelajaran (Erbil \& Kocabaş, 2018). Metode pembelajaran merupakan penjabaran dari pendekatan, sehingga dalam satu pendekatan dapat dijabarkan oleh beberapa metode pembelajaran untuk meningkatkan kemampuan belajar (Miao dkk., 2017).

\section{Model Pembelajaran Materi Penginderaan Jauh Kelas X}

Model pembelajaran berbasis proyek (project based learning) paling tepat untuk materi penginderaan jauh kelas X pada kurikulum 2013 seperti yang tertera pada Tabel 1. Pembelajaran berbasis proyek merupakan pedagogi yang melibatkan siswa dalam melaksanakan dan mengembangkan teori, keterampilan dan teknik untuk memecahkan masalah dunia nyata (Nation, 2008). Siswa diberikan kebebasan dalam menentukan permasalahan yang akan dicarikan jalan keluarnya. Siswa dapat merencanakan dan melakukan penyelidikan sesuai dengan tingkat kemampuannya. Di akhir kegiatan pembelajaran, siswa menyajikan hasil akhir berupa proyek atau produk yang menjadi solusi dari permasalahan yang mereka tentukan. Sementara itu guru berperan sebagai fasilitator. Model pembelajaran berbasis proyek berpengaruh positif terhadap sikap lingkungan siswa, selain itu meningkatkan kreativitas dan pembelajaran yang berkesan (Genc, 2015).

Pendekatan yang tepat diterapkan yaitu menggunakan pendekatan konsep. Siswa diarahkan untuk mengerti suatu bahasan melalui pemahaman konsepkonsep dasar, jenis citra, dan interpretasi citra penginderaan jauh. Alternatif lainnya dapat menggunakan pendekatan saintifik, yakni siswa diarahkan untuk mengamati, bertanya, mengumpulkan informasi, menganalisis, dan mengkomunikasikan 
terkait materi pembelajaran penginderaan jauh yang tertera pada Tabel 1 .

Metode yang bisa digunakan di antaranya metode ceramah, demonstrasi, dan diskusi. Metode ceramah yaitu bentuk pengajaran yang paling lumrah digunakan, dengan cara guru menerangkan materi kepada siswa secara lisan (Behr, 1988). Metode ceramah untuk menekankan pengetahuan, hafalan, pemahaman materi pada siswa. Metode ceramah berpusat pada guru sebagai sumber materi. Metode ceramah lebih menekankan penguasaan materi oleh guru sebagai metode dasar yang sangat diperlukan dalam pengajaran (Spiegel, 1963). Metode demonstrasi yaitu cara penyajian bahan pelajaran dengan memeragakan atau mempertunjukkan kepada siswa suatu proses, situasi atau ben-da tertentu yang sedang dipelajari baik sebenarnya ataupun tiruan (Kiebler \& Woody, 1923). Dengan menampilkan perbedaan peta dan citra penginderaan jauh, membuka link google earth, dan lain sebagainya. Metode diskusi adalah interaksi antara siswa dan siswa atau siswa dan guru untuk menganalisis, memecahkan masalah, menggali atau memperdebatkan topik, atau permasalahan tertentu, sehingga terjadi komunikasi dua arah yang interaktif (Welty, 1989). Sejalan dengan itu, guru dapat mengukur tingkat pemahaman siswa sudah sejauh mana mereka menguasai materi penginderaan jauh.

Tabel 1. Materi Penginderaan Jauh Kurikulum 2013 kelas X

\begin{tabular}{llll}
\hline No & Kompetensi Dasar & Materi Pembelajaran \\
\hline $\mathbf{1}$ & $\begin{array}{l}\text { Memahami dasar-dasar pemetaan, } \\
\text { penginderaan jauh, dan sistem informasi } \\
\text { geografis. }\end{array}$ & $\begin{array}{l}\text { Pengetahuan dasar pemetaan, dasar- } \\
\text { dasar pemetaan, penginderaan jauh, } \\
\text { sistem informasi geografis, jenis peta } \\
\text { dan penggunaannya. }\end{array}$ \\
\hline $\mathbf{2}$ & $\begin{array}{l}\text { Membuat peta tematik wilayah provinsi dan/ } \\
\text { atau salah satu pulau di Indonesia berdasarkan } \\
\text { peta rupa bumi Indonesia. }\end{array}$ & $\begin{array}{l}\text { Jenis citra penginderaan jauh, } \\
\text { interpretasi citra, teori pengolahan data } \\
\text { dalam sistem informasi geografis. }\end{array}$ \\
\hline
\end{tabular}

\section{Model Pembelajaran Materi Penginderaan Jauh Kelas XI}

Materi penginderaan jauh kelas XI kurikulum 2013 seperti pada Tabel 2 tepat menggunakan model pembelajaran berbasis masalah (problem based learning). Model pembelajaran berbasis masalah menitikberatkan siswa sebagai pusat pembelajaran (student ceneterd learning). Guru berperan sebagai fasilitator, siswa terlibat langsung secara aktif dan kreatif dalam sebuah proses pembelajaran. Model pembelajaran ini menstimulus siswa untuk berfikir kritis dan bekerjasama dalam kelompok. Melalui interaksi ini siswa dapat mendapatkan informasi tentang masalah yang dikaji dan menemukan jalan keluar yang tepat. Model berbasis masalah mampu meningkatkan perolehan nilai dan pengetahuan siswa yang lebih melekat kuat (Breton, 1999).

Pendekatan yang tepat diterapkan adalah pendekatan lingkungan dan pemecahan masalah (problem solving). Pendekatan lingkungan mengaitkan lingkungan sekitar dan kegiatan seharihari sebagai sumber belajar. Sedangkan pendekatan pemecahan masalah berangkat dari masalah yang harus dipecahkan melalui praktikum atau pengamatan.

Metode yang digunakan adalah praktikum, proyek, atau studi lapangan. Metode praktikum adalah cara penyampaian bahan ajar dengan memberikan kesempatan berlatih kepada siswa untuk meningkatkan keterampilan sebagai penerapan pengetahuan yang telah dipelajari sebelumnya (Kidd \& Murray, 2020). Praktikum merupakan 
kerja praktek yang lokasinya sesuai dengan tujuan pembelajaran agar siswa memiliki pengalaman belajar yang terencana dan berinteraksi dengan peralatan untuk mengobeservasi fenomena.

Tabel 2. Materi Penginderaan Jauh Kurikulum 2013 kelas XI

\begin{tabular}{clll}
\hline No & \multicolumn{1}{c}{ Kompetensi Dasar } & \multicolumn{3}{c}{ Materi Pembelajaran } \\
\hline 1 & $\begin{array}{l}\text { Menyajikan contoh hasil } \\
\text { penalaran tentang posisi strategis } \\
\text { wilayah Indonesia sebagai poros } \\
\text { maritim dunia dalam bentuk peta, } \\
\text { tabel, dan/atau grafik. }\end{array}$ & $\begin{array}{l}\text { Letak, luas, dan batas wilayah Indonesia. } \\
\text { Indonesia. Perkembangan jalur transportasi dan } \\
\text { perdagangan internasional di Indonesia. Potensi } \\
\text { dan pengelolaan sumber daya kelautan } \\
\text { Indonesia. }\end{array}$ \\
\hline 2 & $\begin{array}{l}\text { Membuat peta persebaran flora } \\
\text { dan fauna di Indonesia dan dunia }\end{array}$ & $\begin{array}{l}\text { Persebaran jenis-jenis flora dan fauna di Indonesia } \\
\text { dan dunia. }\end{array}$ \\
& $\begin{array}{l}\text { yang dilengkapi gambar hewan } \\
\text { dan tumbuhan endemik. }\end{array}$ & & \\
\hline 3 & $\begin{array}{l}\text { Membuat peta persebaran sumber } \\
\text { daya kehutanan, pertambangan, } \\
\text { kelautan, dan } \\
\text { pariwisata di Indonesia. }\end{array}$ & $\begin{array}{l}\text { Potensi dan persebaran sumberdaya alam } \\
\text { kehutanan }\end{array}$ \\
\hline $\begin{array}{l}\text { Membuat peta persebaran } \\
\text { ketahanan pangan nasional, bahan } \\
\text { industri, serta energy baru dan } \\
\text { terbarukan di Indonesia. }\end{array}$ & $\begin{array}{l}\text { Potensi dan persebaran sumber daya pertanian, } \\
\text { perkebunan, perikanan, dan peternakan untuk } \\
\text { ketahanan pangan nasional. Potensi dan persebaran } \\
\text { sumber daya untuk penyediaan bahan industri. }\end{array}$ \\
& $\begin{array}{l}\text { Potensi dan persebaran sumber daya untuk } \\
\text { penyediaan energi baru dan terbarukan. }\end{array}$ \\
\hline
\end{tabular}

\section{Model Pembelajaran Materi \\ Penginderaan Jauh Kelas XII}

Melihat pada Tabel 3, model pembelajaran untuk materi penginderaan jauh kelas XII kurikulum 2013 tepat menggunakan model pembelajaran berbasis penelitian (Research Based Learning). Para pendukung pembelajaran berbasis penelitian telah menunjukkan perlunya mengembangkan antuasiasme dalam pertanyaan kritis dan solusi kreatif. Di era informasi seperti saat ini begitu mudah memperoleh data melalui media elektronik, guru harus menantang siswa untuk menggunakan pengetahuan yang sudah ada (Guinness, 2012). Melalui model pembelajaran berbasis penelitian menjadikan siswa sebagai penghasil pengetahuan dan pembelajar sejati (Walkington dkk., 2011), dengan menggabungkan bukti dari beberapa literatur yang lebih luas sehingga pedagogi seperti itu memberikan ruang untuk bersikap kritis dan konstruktif (Lambert, 2009).

Pendekatan yang digunakan berupa pemecahan masalah yang berkaitan dengan lingkungan sekitar tempat tinggal siswa. Metode yang diterapkan dapat berupa praktikum di laboratorium dan lapangan. Langkah-langkahnya diawali dengan menentukan peta tematik yang akan dibuat dari citra penginderaan jauh, misalkan peta penggunaan lahan, peta jaringan jalan, dan peta geomorfologi. Tentukan citra yang akan digunakan, misalnya citra Landsat dan citra Quickbird. Kemudian tentukan perangkat lunak yang akan digunakan, misalnya QGIS, ArcGIS, ENVI, atau bisa juga dengan cara manual tanpa menggunakan perangkat lunak. Langkah selanjutnya melakukan interpretasi citra penginderaan jauh sampai menghasilkan peta tentatif. Survei lapangan dilakukan untuk uji akurasi hasil interpretasi. Data hasil survei 
dijadikan dasar untuk melakukan hasil. Terakhir mempresentasikan peta reinterpretasi sehingga menghasilkan peta akhir yang siap digunakan.

Tabel 3. Kurikulum 2013 kelas XII

\begin{tabular}{clll}
\hline No & \multicolumn{1}{c}{ Kompetensi Dasar } & \multicolumn{2}{c}{ Materi Pembelajaran } \\
\hline 1 & $\begin{array}{l}\text { Menganalisis jaringan transportasi dan tata } \\
\text { guna lahan dengan peta dan/ atau citra dan sistem informasi geografis. }\end{array}$ \\
penginderaan jauh serta sistem informasi & $\begin{array}{l}\text { Interpretasi peta dan pengolahan citra } \\
\text { peografis kaitannya dengan pengembangan }\end{array}$ & $\begin{array}{l}\text { penginderaan jauh terkait jaringan } \\
\text { transportasi dan tata guna lahan. }\end{array}$ \\
& $\begin{array}{l}\text { potensi wilayah dan kesehatan lingkungan. } \\
\text { Menyajikan peta tematik berdasarkan }\end{array}$ & Analisis keruangan pada sistem \\
pengolahan citra penginderaan jauh dan & informasi geografis terkait potensi \\
& $\begin{array}{l}\text { sistem informasi geografis untuk } \\
\text { pengembangan potensi wilayah dan kesehatan lingkungan. } \\
\text { kesehatan lingkungan. }\end{array}$
\end{tabular}

\section{KESIMPULAN}

Model pembelajaran berbasis proyek (project based learning) paling tepat untuk materi penginderaan jauh kelas X pada kurikulum 2013. Pembelajaran berbasis proyek merupakan pedagogi yang melibatkan siswa dalam melaksanakan dan mengembangkan teori, keterampilan dan teknik untuk memecahkan masalah dunia nyata. Siswa diberikan kebebasan dalam menentukan permasalahan yang akan dicarikan solusinya. Materi penginderaan jauh kelas XI pada kurikulum 2013 tepat menggunakan model pembelajaran berbasis masalah (problem based learning). Model pembelajaran berbasis masalah menitikberatkan pusat pembelajaran kepada siswa. Pengajar memfasilitasi siswa agar terlibat langsung dalam proses pembelajaran. Model pembelajaran ini mendorong siswa untuk berfikir kritis dan bekerjasama dalam kelompok. Sedangkan untuk materi penginderaan jauh kelas XII pada kurikulum 2013 tepat menggunakan model pembelajaran berbasis penelitian (Research Based Learning). Melalui Research Based Learning menjadikan siswa sebagai penghasil pengetahuan dan pembelajar sejati, dengan menggabungkan bukti dari beberapa literatur yang lebih luas sehingga pedagogi seperti itu memberikan ruang untuk bersikap kritis dan konstruktif.

\section{DAFTAR PUSTAKA}

Abdel-Rahman, E. M., \& Ahmed, F. B. (2008). The application of remote sensing techniques to sugarcane (Saccharum spp. hybrid) production: A review of the literature. International Journal of Remote Sensing, 29(13), 3753-3767. https://doi.org/10.1080/01431160701 874603

Alkin-Sahin, S. (2015). The relationship between the educational beliefs and learning approaches. Anthropologist, 22(2), 301-308. https://doi.org/10.1080/09720073.20 15.11891881

Behr, A. L. (1988). Exploring the Lecture Method: An empirical study. Studies in Higher Education, 13(2), 189-200. https://doi.org/10.1080/03075078812 331377866

Belmonte, J. L., Cabrera, A. F., Núñez, J. A. L., \& Sánchez, S. P. (2019). Formative transcendence of flipped learning in mathematics students of secondary education. Mathematics, $7(12)$. https://doi.org/10.3390/MATH71212 26 
Bergsteiner, H., \& Avery, G. C. (2014). The twin-cycle experiential learning model: reconceptualising Kolb's theory. Studies in Continuing Education, 36(3), 257-274. https://doi.org/10.1080/0158037X.20 14.904782

Breton, G. (1999). Some empirical evidence on the superiority of the problem-based learning (PBL) method. International Journal of Phytoremediation, 21(1), 1-12. https://doi.org/10.1080/09639289933 1008

Cerezo, R., Bernardo, A., Esteban, M., \& Tuero, M. S. y E. (2015). Programas para la promoción de la autorregulación en educación superior: un estudio de la satisfacción diferencial entre metodología presencial y virtual. European Journal of Education and Psychology, 8(1), 30-36. https://doi.org/10.1016/j.ejeps.2015. 10.004

Cheung, M., \& Delavega, E. (2014). FiveWay Experiential Learning Model for Social Work Education. Social Work Education, 33(8), 1070-1087. https://doi.org/10.1080/02615479.20 14.925538

Erbil, D. G., \& Kocabaş, A. (2018). Cooperative Learning as a Democratic Learning Method. Journal of Research in Childhood Education, 32(1), 81-93. https://doi.org/10.1080/02568543.20 17.1385548

Erskine, L., \& Johnson, S. D. (2012). Effective Learning Approaches for Sustainability: A Student Perspective. Journal of Education for Business, $87(4)$,

198-205. https://doi.org/10.1080/08832323.20 11.590162

Everaert, P., Opdecam, E., \& Maussen, S. (2017). The relationship between motivation, learning approaches, academic performance and time spent. Accounting Education, 26(1), 78-107.

https://doi.org/10.1080/09639284.20 16.1274911

Fathrunnadi Shalihati, S., Kunci, K., Jauh, P., Informasi Geografi, S., Kelautan, S., \& Negara Maritim, P. (2014). Pemanfaatan Penginderaan Jauh Dan Sistem Informasi Geografi Dalam Pembangunan Sektor Kelautan Serta Pengembangan Sistem Pertahanan Negara Maritim. 2(Unclos 1982), 115-126.

Genc, M. (2015). The project-based learning approach in environmental education. International Research in Geographical and Environmental Education, 24(2), 105-117. https://doi.org/10.1080/10382046.20 14.993169

Gréhaigne, J. F., Wallian, N., \& Godbout, P. (2006). Physical Education and Sport Pedagogy Tactical-decision learning model and students ' practices Tactical-decision learning model and students, practices. Physical Education and Sport Pedagogy, February 2013, 37-41.

Guinness, P. (2012). Research-Based Learning: Teaching Development Through Fieldschools. Journal of Geography in Higher Education, 36(3), 329-339. https://doi.org/10.1080/03098265.20 12.696188

Huang, B., Hew, K. F., \& Lo, C. K. (2019). Investigating the effects of gamification-enhanced flipped learning on undergraduate students' behavioral and cognitive engagement. Interactive Learning Environments, 27(8), 1106-1126. https://doi.org/10.1080/10494820.20 18.1495653

Kidd, W., \& Murray, J. (2020). The Covid19 pandemic and its effects on teacher education in England: how teacher 
educators moved practicum learning online. European Journal of Teacher Education, 43(4), 542-558. https://doi.org/10.1080/02619768.20 20.1820480

Kiebler, E. W., \& Woody, C. (1923). The individual laboratory versus the demonstration method of teaching physics. Journal of Educational Research, 7(1), 50-58. https://doi.org/10.1080/00220671.19 23.10879328

Korkmaz, O., \& Karakus, U. (2009). The impact of blended learning model on student attitudes towards geography course and their critical thinking dispositions and levels. The Turkish Online Journal of Distance Education, 8(4), 51-63.

Kwon, J. E., \& Woo, H. R. (2017). The impact of flipped learning on cooperative and competitive mindsets. Sustainability (Switzerland), 10(1), 1-15. https://doi.org/10.3390/su10010079

Lambert, C. (2009). Pedagogies of participation in higher education: A case for researchbased learning. Pedagogy, Culture and Society, 17(3), 295-309. https://doi.org/10.1080/14681360903 194327

Manzano-Agugliaro, F., Castro-García, M., Pérez-Romero, A. M., GarcíaCruz, A., Novas, N., \& SalmerónManzano, E. (2016). Alternative methods for teaching cadastre and remote sensing. Survey Review, 48(351), 450-459. https://doi.org/10.1179/1752270615 Y.0000000046

Miao, Y. Z., Ma, X. P., \& Bu, S. P. (2017). Research on the Learning Method Based on PCA-ELM. Intelligent Automation and Soft Computing, 23(4), 637-642. https://doi.org/10.1080/10798587.20 17.1316071
Mountrakis, G., \& Triantakonstantis, D. (2012). Inquiry-Based Learning in Remote Sensing: A Space Balloon Educational Experiment. Journal of Geography in Higher Education, 36(3), 385-401. https://doi.org/10.1080/03098265.20 11.638707

Nation, M. L. (2008). Project-based learning for sustainable development. Journal of Geography, 107(3), 102111.

https://doi.org/10.1080/00221340802 470685

Núñez, J. A. L., Belmonte, J. L., Guerrero, A. J. M., \& Sánchez, S. P. (2020). Effectiveness of innovate educational practices with flipped learning and remote sensing in earth and environmental sciences-An exploratory case study. Remote Sensing, 12(5). https://doi.org/10.3390/rs12050897

Ridwana, R., \& Himayah, S. (2020). Utilization of Remote Sensing Technology and Geographic Information Systems for Tourism Development. International Journal of Applied Sciences in Tourism and Events, 4(2), 158-169. https://doi.org/10.31940/ijaste.v4i2.2 042

Ruhyati, N. A., \& Banowati, E. (2019). Edu Geography Strategi Guru Geografi dalam Pembelajaran Penginderaan Jauh Kelas XII di SMA. Edu Geography, 7(1), 19-28.

Selesho, J. M. (2012). Learning Model as a Strategy to Improve Quality of Academic Programmes. Journal of Social Sciences, 33(2), 147-154. https://doi.org/10.1080/09718923.20 12.11893094

Spiegel, S. (1963). The Lecture Method of Teaching History. The Social Studies, 54(1), 9-10. https://doi.org/10.1080/00220973.19 41.11018514 
Sugiharto. (2020). Geographical students' learning outcomes on basic political science by using cooperative learning model with Group Investigation (GI) type in State University of Medan, Indonesia. Journal of Human Behavior in the Social Environment, 30(4), 447-456. https://doi.org/10.1080/10911359.20 19.1696261

Tse, W. S., Choi, L. Y. A., \& Tang, W. S. (2019). Effects of video-based flipped class instruction on subject reading motivation. British Journal of Educational Technology, 50(1), 385398.

https://doi.org/10.1111/bjet.12569

Urhahne, D. (2020). Learning approaches. Educational Psychology, 40(5), 533-
534.

https://doi.org/10.1080/01443410.20 20.1755503

Walkington, H., Griffin, A. L., KeysMathews, L., Metoyer, S. K., Miller, W. E., Baker, R., \& France, D. (2011). Embedding research-based learning early in the undergraduate geography curriculum. Journal of Geography in Higher Education, 35(3), 315-330. https://doi.org/10.1080/03098265.20 11.563377

Welty, W. M. (1989). Discussion Method Teaching. Change: The Magazine of Higher Learning, 21(4), 40-49. https://doi.org/10.1080/00091383.19 89.9939866 